\title{
Is it really safe to evaluate symptomatic extensor carpi ulnaris tendon instability by magnetic resonance imaging (MRI)?
}

\author{
Tahir ÖzTÜRK, Mehmet Burtaç EREN \\ From the Gaziosmanpasa University School of Medicine, Department of Orthopaedics and Traumatology, Tokat, Turkey
}

The extensor carpi ulnaris (ECU) tendon is in the sixth extensor compartment of the wrist and is isolated from other tendons by a different sheath. Extensor carpi ulnaris pathologies are characterized by pain locally localized to the wrist ulnar side. Outpatient records and wrist MRI (magnetic resonance imaging) tests were retrospectively scanned between January 2018 and July 2019. By examining the anamnesis and examination notes of the patients in the outpatient clinic records, patients with wrist ulnar side pain, pain or sensitivity on the ulnar styloid and provocation test (synergy) were assigned to the first study group (Group 1).The second study group was composed of patients who underwent wrist MR for the diagnosis or differential diagnosis of a synovial cyst around the wrist, without ulnar side pain (Group 2). While evaluating MR images in the axial plane, the depth and width of the ulnar groove, thickness of the ECU tendon were measured. The position of the ECU tendon relative to the ulnar groove and the forearm rotation during the shooting were recorded. 105 cases evaluated, there were 41 cases in the symptomatic subgroup and 64 cases in the asymptomatic subgroup. Among all patients, the mean patient age was 38.05. In the evaluation according to whether cases were symptomatic or not, there was no significant relationship between being symptomatic and the degree of instability and MR withdrawal position.

The authors declares that there is no conflict of interest regarding the publication of this article. There is no funding source.

Ethical approval : This scientific study has been evaluated by Gaziosmanpaşa University Clinical Research Ethics Committee at the design stage with the project number 20KAEK-091 and has been found scientifically and ethically appropriate.
Our study suggests that ECU instability in MR is not a specific condition, and detection of MR in instability may not be associated with a patient's symptoms.

Keywords : extensor carpi ulnaris tendon ; ECU instability ; wrist MRI ; morphometric analysis

\section{INTRODUCTION}

The extensor carpi ulnaris (ECU) tendon is in the sixth extensor compartment of the wrist and is isolated from other tendons by a different sheath. The ECU tendon and lower sheath probably help stabilize the distal radioulnar joint and distal carpal row (1). Tendon sheath reinforced with a fibrous tissue called "linea jugata", extends from the medial attachment point, which is resistant to medial and volar subluxation in the ulnar groove of the ECU tendon, around 1.5 to $2 \mathrm{~cm}$ (2). Unlike other extensor compartments, the ECU tendon has

Tahir Öztürk,

Mehmet Burtaç Eren

Gaziosmanpasa University School of Medicine, Department of Orthopaedics and Traumatology, Tokat, Turkey

Correspondence : Dr. Mehmet Burtaç Eren, Department of Orthopaedics and Traumatology Gaziosmanpasa University, Kaleard1 District Muhittin Fisunoglu Street, 60100 Tokat, Turkey. Tel. : +90 356212 9500-1282, GSM : +90532 4836612

E-mail : mehmetburtac@hotmail.com

- 2021, Acta Orthopædica Belgica.

Acta Orthopædica Belgica, Vol. 87 - 2 - 2021 
a structure that allows it to turn comfortably around the ulna, thanks to its retinaculum and its lack of direct osseous support (3).

Although tendovaginitis specific to other extensor compartments with a similar anatomical structure has been well defined, to date, interest in ECU tendinitis has been relatively low. However, in recent years there has been an increased interest in ECU tendon pathologies, in parallel with the increased interest in dart throwing motion, which is frequently used during daily activities. The ECU tendon plays a dominant role in archery and dart sports. Today, the ECU tendon is known to be frequently damaged in sports injuries that occur during sports such as tennis, water polo, polo, golf and golf hockey $(4,5)$. Beyond professional sports, the ECU often functions actively during daily life when opening bottles or jars, opening door handles, and in intensive use of the keyboard and mouse. The first classification for ECU tendon pathologies that are active in a wide range of functions was carried out by M. Garcia-Elias (6). It is known that ECU tendinitis has the second highest frequency among wrist tendinopathies. However, there is no adequate epidemiological study on ECU tendinopathies. Considering that the most common de Quervain's tenosynovitis was defined 125 years ago, it is clear that the interest shown in this issue is not sufficient (7).

Most of the studies on ECU tendon instability consist of limited case series and cohort studies of sports groups (4,8-11). There is no epidemiological study in the literature investigating the population incidence and prevalence of ECU tendon instability. Although the ultrasonographic prevalence of ECU tendinopathy in volunteers has been investigated, no studies with a similar design have been performed for ECU tendon instability (12-14).

Most of the reported injuries occur during sports activities in which the wrist is actively used. The biomechanical mechanism that causes instability and ECU tendon pathologies in athletes can often be seen as exposure to axial and compressive load during forced supination and ulnar deviation. These types of injuries are often caused by the trauma of "fat shot" in golfers. In tennis players, injury may occur with forehand stroke in the dominant hand and double-handed backhand stroke in the non-dominant hand. It is also known that the ECU tendon plays a major role in the midcarpal pronation movement, as has been demonstrated in biomechanical cadaver studies (1). It is clear that the ECU tendon will be exposed to constant stress inside and outside the sheath due to the midcarpal pronation movement by holding the wrist in a fixed position and with difficult supination-pronation periods. Additionally the wrist joint, which does not have a hinged structure, does not have collateral ligaments, so the ECU on the medial side and the APL tendons in the lateral act as extra-articular stabilizers $(15,16)$. Therefore, ECU tendon exposed to forces during ulnar-radial deviation, such as golf, tennis, basketball, archery and polo $(1,16)$.

Extensor carpi ulnaris tendon pathologies are characterized by pain locally localized to the wrist ulnar side. Usually, pain occurs on the dorsoulnar side of the wrist during supination, flexion and ulnar deviation (17,18). In previous studies, ultrasound sonography (USG) and magnetic resonance (MR) have been used in clinically correlated cases to evaluate ECU tendon instabilities (subluxation or dislocation) $(4,19,20)$. In an MRI-based study with cadavers, the ECU tendon was found to be prone to subluxation at maximum supination (21). In cases with ECU instability, the pain that is usually triggered by supination movement may be due to this patho-mechanical reason. Also, for this reason, the ECU tendon may be mistakenly unstable in a radiological examination performed in the supination position. While this is a normal pathomechanical feature, it is possible that it may lead to a diagnosis of excessive ECU instability. It is not known whether this well-known biomechanical property can lead to a diagnosis of instability in an unstable tendon during radiological evaluations, and beyond that, if it affects diagnostic accuracy in an asymptomatic or symptomatic patient (22-24).

In our study, we aimed to evaluate the MR results of patients with and without ulnar side pain, the MR draft position and the position of the ECU tendon in the groove of the ECU and to evaluate the relationship between the position of the ECU tendon in the groove. In our evaluation, taking into account whether the patients are symptomatic or 
not, we aimed to test whether the ECU instability detected in the MR examination is really clinically significant.

\section{PATIENTS AND METHODS}

Following approval from the clinical research ethics committee of Tokat Gaziosmanpaşa University, outpatient records and wrist MRI (magnetic resonance imaging) tests were retrospectively scanned. Patients who applied to our outpatient clinic between January 2018 and July 2019 and had wrist MR were included in the evaluation. By examining the anamnesis and examination notes of the patients in the outpatient clinic records, patients with wrist ulnar side pain, pain or sensitivity on the ulnar styloid and provocation test (synergy) (25) were assigned to the first study group (Group 1). The second study group was composed of patients who underwent wrist MR for the diagnosis or differential diagnosis of a synovial cyst around the wrist, without ulnar side pain (Group 2).

The inclusion criteria for the study were determined as being 18-75 years old, receiving an unreinforced MR examination in our institution and the presence of detailed anamnesis and physical examination findings. The exclusion criteria for the study were congenital upper extremity malformation, wrist operation, wrist and peripheral fractures and injuries and known inflammatory joint disease.

MR was performed using a device with $1.5 \mathrm{~T}$ magnetic field strength for MR shots (Signa Explorer, GE Healthcare, New York, USA).

While the design of the study groups, medical record files, clinical tests were carried out mainly by the author (TO), the evaluation of the MRI images was carried out by the other author (MBE), blindly to the group information.

MRI images in the axial plane, the depth and width of the ulnar groove were measured. For width, the highest points of the notches on both sides of the ulnar groove were taken; while measuring the depth, the distance from the measured width line to the shallowest point of the groove was taken. Shallow location was determined and measured. After ulnar groove measurements, the thickness
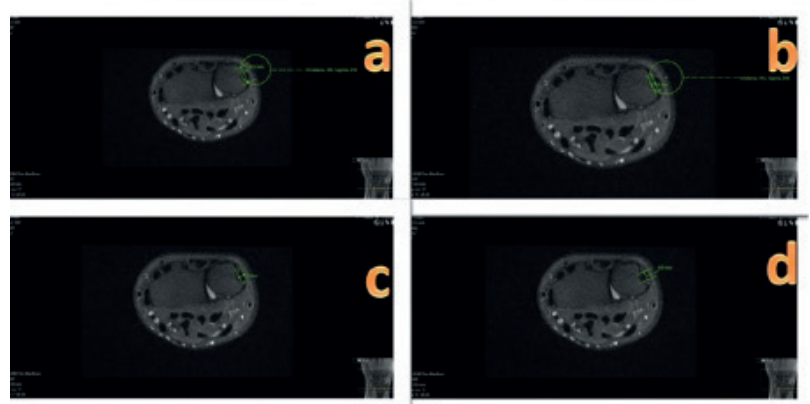

Figure 1. - Morphometric analysis of ECU tendon and ulnar groove: a) groove width b) groove depth c) ECU tendon depth d)ECU tendon width.
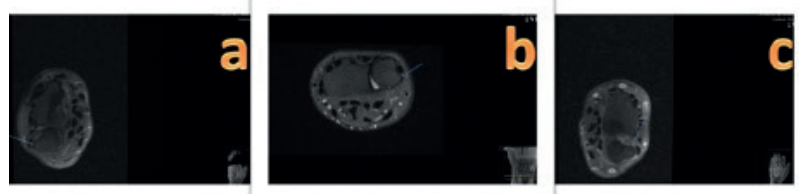

Figure 2. - Determination of forearm rotation according to ulnar styloid line: a) neutral b) pronation c) supination.

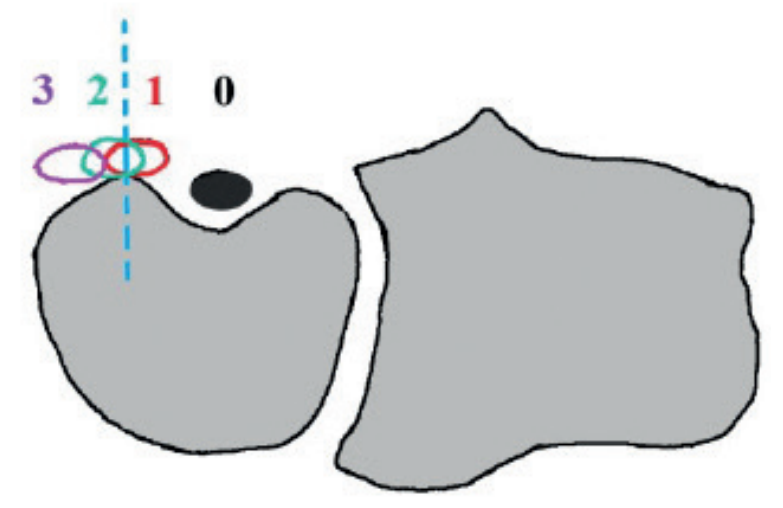

Figure 3. - Instability score according to the ECU tendon position.

of the ECU tendon (in the anterior posterior plane), width (transverse length) and region of interest(ROI) area were measured in the axial plane (20). The position of the ECU tendon relative to the ulnar groove and the forearm rotation during the shooting were recorded. (Figure 1-2).

The evaluation of the ECU tendon by groove was performed according to the vertical line drawn from the most medial edge of the ulnar groove in axial plane sections. The ECU tendon was evaluated on the groove side of the line and assigned as Grade 

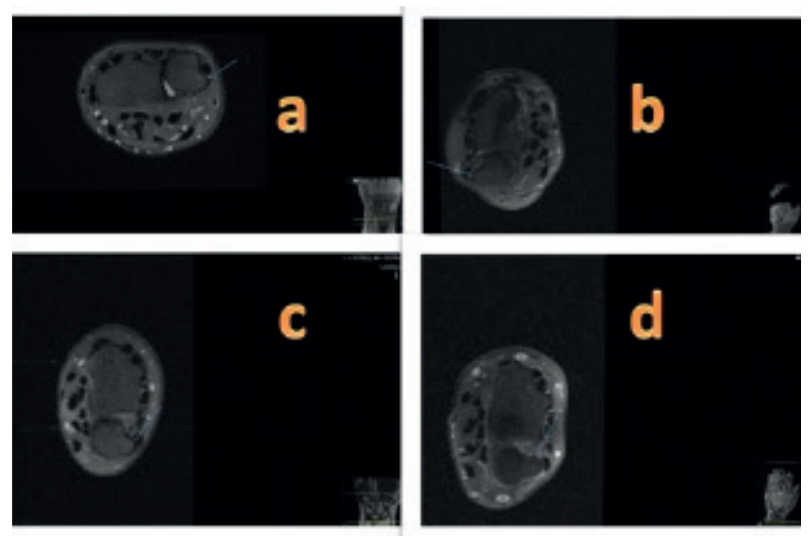

Figure 4. - Examples of instability scoring performed in MR evaluation a) Grade 0, b) Grade 1, c) Grade 2, d) grade 3.

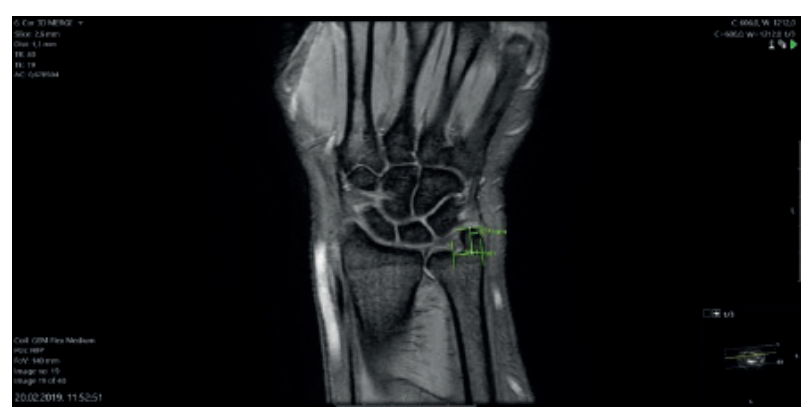

Figure 5. - Morphometric analysis of ulnar styloid ; calculation of width and height of styloid process.

0 if there was no contact with the line and grade 3 if there was no contact with the line completely dislocated from the groove. Grade 2 was assigned if the line passed between $51 \%$ and $99 \%$ of the groove. Forearm rotation also was determined according to this drawn line $(20,22,26)$. (Figure 3-4).
In the images taken in the coronal plane ulnar styloid width-length was calculated. (Figure 5).

Comparison between groups was mainly carried out between the main working groups. In addition, sub groups were created according to forearm rotation and grade score in ECU tendon instability during MRI. Distribution of quantitative variables according to MR instability grade scoring and forearm rotation position has evaluated. Relationship between forearm rotation and MRI instability grade score has also evaluated.

The Mann-Whitney U test was used to evaluate the qualitative and quantitative variables between the groups. The presence of symptomatic patients and their evaluation according to the wrist position were evaluated by the Pearson chi-square test analysis. A P value of $<0.01$ was considered statistically significant. $\mathrm{P}$ values less than 0.05 were also accepted as statistically significant. The software used was IBM SPSS Statistics 19 (SPSS Inc., an IBM Co., Somers, NY).

\section{RESULTS}

Of the 105 cases evaluated, there were 41 cases in the symptomatic subgroup and 64 cases in the asymptomatic subgroup. Among all patients, the mean patient age was 38.05 years (range, 18-75 years). 64 of the cases $(64.8 \%)$ were female and $37(35.2 \%)$ were male. According to the quantitative variables (measurements evaluating the ulnar groove), the relationship between the wrist position and the condition of the ECU tendon in the ulnar groove has evaluated. There is no

Table I. - Distribution of quantitative variables by wrist

\begin{tabular}{|l|c|c|c|c|}
\hline \multirow{2}{*}{} & \multicolumn{3}{|c|}{ Forearm rotation position } & \multirow{2}{*}{$\mathrm{p}$} \\
\cline { 2 - 5 } & Pronation $(n=37)$ & Neutral $(n=33)$ & Supination $(n=35)$ & 0.234 \\
\hline Age & $35.03 \pm 13.7$ & $40.91 \pm 14.35$ & $38.54 \pm 15.35$ & 0.615 \\
\hline ECU groove width $(\mathrm{mm})$ & $8.35 \pm 0.58$ & $8.26 \pm 0.59$ & $8.41 \pm 0.62$ & 0.239 \\
\hline ECU groove depth & $2.08 \pm 0.24$ & $2.18 \pm 0.33$ & $2.19 \pm 0.31$ & 0.112 \\
\hline Groove-opening angle & $136.08 \pm 7.55$ & $134.22 \pm 8.57$ & $131.92 \pm 8.95$ & 0.250 \\
\hline ECU tendon width $(\mathrm{mm})$ & $5.16 \pm 0.6$ & $5.11 \pm 0.53$ & $4.95 \pm 0.53$ & 0.224 \\
\hline Tendon thickness & $2.29 \pm 0.24$ & $2.37 \pm 0.28$ & $2.41 \pm 0.32$ & 0.904 \\
\hline Styloid base width & $7.86 \pm 0.61$ & $7.84 \pm 0.7$ & $7.91 \pm 0.78$ & 0.094 \\
\hline Styloid process length & $6.27 \pm 0.76$ & $6.51 \pm 0.83$ & $6.68 \pm 0.83$ & \\
\hline
\end{tabular}

$\mathrm{p}$ : Independent sample t-test. 
Table II. - Distribution of quantitative variables according to MR instability grade scoring

\begin{tabular}{|l|c|c|c|c|}
\hline \multirow{2}{*}{} & \multicolumn{3}{|c|}{ Grade } & \multicolumn{2}{c|}{$\mathrm{p}$} \\
\cline { 2 - 5 } & 0 & 1 & $38.54 \pm 15.54$ & $39 \pm 16.42$ \\
\hline Age & $37.18 \pm 12.93$ & $8.23 \pm 0.55$ & $8.35 \pm 0.63$ & 0.865 \\
\hline ECU groove width (mm) & $8.44 \pm 0.62$ & $2.21 \pm 0.32$ & $2.16 \pm 0.3$ & 0.302 \\
\hline ECU groove depth & $2.09 \pm 0.27$ & $134.54 \pm 9.34$ & $132.24 \pm 7.06$ & 0.532 \\
\hline Groove-opening angle & $134.6 \pm 8.3$ & $5.03 \pm 0.57$ & $5.07 \pm 0.55$ & 0.845 \\
\hline ECU tendon width (mm) & $5.1 \pm 0.56$ & $2.35 \pm 0.27$ & $2.39 \pm 0.38$ & 0.824 \\
\hline Tendon thickness & $2.34 \pm 0.25$ & $7.89 \pm 0.81$ & $7.92 \pm 0.72$ & 0.883 \\
\hline Styloid base width & $7.83 \pm 0.58$ & $6.66 \pm 0.8$ & $6.55 \pm 0.83$ & 0.108 \\
\hline Styloid process length & $6.29 \pm 0.8$ & & & \\
\hline
\end{tabular}

$\mathrm{p}$ : Independent sample t-test.

Table III. - Relationship of forearm rotation with MRI instability grade scoring

\begin{tabular}{|c|c|c|c|c|c|c|}
\hline & \multicolumn{3}{|c|}{ Forearm rotation position } & & \multirow{3}{*}{$\mathrm{p}$} \\
\hline & & Pronation & Neutral & Supination & & \\
\hline & & 37 & 33 & 35 & 105 & \\
\hline \multirow[t]{3}{*}{ Grade } & 0 & $30(81.1)$ & $11(33.3)$ & $4(11.4)$ & 45 & \multirow{3}{*}{$*<0.001$} \\
\hline & 1 & $7(18.9)$ & $19(57.6)$ & $13(37.1)$ & 39 & \\
\hline & 2 & $0(0)$ & $3(9.1)$ & $18(51.4)$ & 21 & \\
\hline
\end{tabular}

$\mathrm{p}$ : Independent sample t-test. * Statistically significant $(\mathrm{p}<0.05)$.

Table IV. — Distribution of forearm rotation and MR instability grade scoring by symptom.

\begin{tabular}{|l|l|c|c|c|}
\hline \multirow{2}{*}{$\begin{array}{l}\text { Forearm } \\
\text { rotation } \\
\text { position }\end{array}$} & \multirow{2}{*}{ Grade } & \multicolumn{2}{|c|}{ Symptom } & \multirow{2}{*}{$\mathrm{p}$} \\
\cline { 2 - 4 } & Negative & Positive & \\
\cline { 2 - 4 } Pronation & 0 & $17(77.3)$ & $\mathrm{n}(\%)$ & \\
\cline { 2 - 4 } & 1 & $5(22.7)$ & $2(13.3)$ & \\
\cline { 2 - 4 } & 2 & $0(0)$ & 0.474 \\
\hline \multirow{5}{*}{ Neutral } & 0 & $7(30.4)$ & $4(40)$ & \multirow{2}{*}{0.841} \\
\cline { 2 - 4 } & 1 & $14(60.9)$ & $5(50)$ & \\
\cline { 2 - 4 } Supination & 2 & $2(8.7)$ & $1(10)$ & \\
\cline { 2 - 4 } & 0 & $1(5.3)$ & $3(18.8)$ & \multirow{2}{*}{0.081} \\
\cline { 2 - 4 } & 1 & $5(26.3)$ & $8(50)$ & \\
\cline { 2 - 4 } & 2 & $13(68.4)$ & $5(31.3)$ & \\
\hline
\end{tabular}

$\mathrm{p}:$ Independent sample t-test.

significant difference between the groups. Again, it was seen that there was no significant difference in the evaluation between gender and side and the quantitative variables (Table 1-2).

The distribution of the wrist position in MR was found to be balanced. None of the patients, including symptomatic cases, had Grade 3 complete dislocation. There were 21 cases of Grade 2, 39 cases of Grade 1 and 45 cases of Grade 0 . As seen in Table 3, there was clearly a relationship between the
Table V. — ECU tendon instability grade distribution in the groups

\begin{tabular}{|l|c|c|}
\hline & $\begin{array}{c}\text { Group 1 } \\
(\text { Symptomatic) } \\
\mathrm{n}=41\end{array}$ & $\begin{array}{c}\text { Group 2 } \\
\text { Asymptomatic } \\
\mathrm{n}=64\end{array}$ \\
\hline Normal (Grade 0) & $\begin{array}{c}20 \\
(\% 48,8)\end{array}$ & $\begin{array}{c}25 \\
(\% 39,1)\end{array}$ \\
\hline $\begin{array}{l}\text { Subluxation } \\
\text { (Grade 1) }\end{array}$ & $\begin{array}{c}15 \\
(\% 36,6)\end{array}$ & $\begin{array}{c}24 \\
(\% 37,5)\end{array}$ \\
\hline $\begin{array}{l}\text { Dislocation } \\
\text { (Grade 2) }\end{array}$ & 6 & 15 \\
$(\% 14,6)$ & $(23,4)$ \\
\hline $\begin{array}{l}\text { Number of medial } \\
\text { translation }\end{array}$ & $\begin{array}{c}21 \\
(\% 51,2)\end{array}$ & $\begin{array}{c}39 \\
(\% 60,9)\end{array}$ \\
\hline
\end{tabular}

wrist position and the position of the ECU tendon in the groove, regardless of symptoms. Grade 2-3 instability was not observed at all in the pronation position, and in 30 cases $(81.1 \%)$ the ECU tendon was observed in the groove. However, when the wrist was switched from the neutral to the supination, the cases where the ECU tendon was subluxated from the groove was clearly increased, with grade 2 subluxation observed in $51.4 \%$ of cases (Table 3).

In the evaluation according to whether cases were symptomatic or not, there was no significant relationship between being symptomatic and the degree of instability and MR withdrawal position. 
Only 6 cases who were symptomatic were evaluated as Grade 2 ; forearm rotation was supination in 5 cases and neutral in 1 case. In contrast, in the group of patients who were asymptomatic, 15 cases were evaluated as Grade 2 (Table 4, 5).

\section{DISCUSSION}

ECU tendinopathy and dislocation have become symptomatic and are frequently researched, particularly in professional athletes. The reason for this is the role of the ECU. The sudden, hard, forced and continuous use on the ulnar side by the athletes causes chronic irritation symptoms, supination, and ulnar deviation triggers ECU instability $(8,27)$.

Some authors have suggested that there is a relationship between the morphological appearance of the ulnar groove and its shallow, short and flat and ECU instability. Singh et al., in their cadaver study, classified the distal ulna groove according to the $\mathrm{C}, \mathrm{L}$ and $\mathrm{S}$ types; they reported that the $\mathrm{S}$ type is shallower, and the $\mathrm{L}$ type is flatter. With MR evaluation in cadavers, dislocation rates of $8 \%$ for $\mathrm{C}$ type, 33\% in L type and $47 \%$ in $\mathrm{S}$ type, were shown (28).

Studies reporting that there is no significant relationship between anatomical parameters and instability are also available in the literature. Iorio et al., in their study retrospectively screening 60 cases, evaluated patients with ulnar side pain and those who did not, in two different groups. They reported that there was no difference between the two groups in terms of morphological parameters (20).

In our study, there was no significant relationship between the assessment of instability in MR and anatomical parameters (ECU groove width $(\mathrm{mm})$, ECU groove depth, groove-opening angle, ECU tendon width $(\mathrm{mm})$, tendon thickness, styloid base width or styloid process length). That finding has suggested that when evaluate tendon instability, benefits of this parameters are questionable.

It has been reported by many authors that ECU instability occurs in all wrist and wrist positions in both symptomatic and asymptomatic cases. In a study focusing on the comparison of MR images, Jeantroux et al. found ECU subluxation in supination in $69 \%$ of 16 symptomatic athletes, while no subluxation was observed in pronation (29). Burgess et al. investigated MR images of 24 computer users who were symptomatic and asymptomatic, and detected $58.4 \%$ instability in cases in neutral and supination positions and $8 \%$ dislocation, and only one of these dislocation cases was asymptomatic and reported as symptomatic (30). Petchprapa et al. evaluated the position of the ECU tendon in the ulnar groove in pronation, neutral and supination positions with MR imaging in 38 wrists of 19 asymptomatic volunteers; only in $15.8 \%$ of the cases the ECU tendon remained in the ulnar groove in each position (22).

In our study, a significant relationship was found between the forearm supination position and instability pain, in line with the available literature data. In addition, when evaluated with the finding that the morphological parameters of the patient group with positive symptomatic and examination findings did not differ significantly compared to the asymptomatic cases, this suggests that the morphological evaluations and instability assessments made in the MR examination may be misleading.

MRI is not the only modality that evaluates ECU instability. Studies evaluating ECU tendon instability with USG are also available (22-24).

In particular, in our asymptomatic control group, instability was found more frequently in supination. The ECU tendon physiologically changes from the ulnar groove to the subluxated or dislocated position displaced medially, with the wrist passing to the neutral and then supination position before pronation. When we are evaluating tendon instability rates independent from wrist position, medial translation rate in symptomatic cases was $51,2 \%$, whereas medial translation in asymptomatic cases was significantly higher at 60,9\%.(Table 5) This suggested that subluxation in MR would not be significant even if there were isolated ECU symptoms such as clinically confirmed ulnar side pain and a positive provocation test.

Boutin et al. achieved real-time imaging of the wrist with dynamic MRI. In supination, ECU instability was observed more frequently than in pronation, with $36 \%$ subluxation and $43 \%$ dislocation, and $14 \%$ subluxation and $7 \%$ dislocation 
in pronation (31). In their evaluation of ECU tendon instability, Kaiser et al. evaluated whether there was a correlation was observed between ECU tendon subluxation or dislocation in the MR report and the findings of the surgical report in order to relate the wrist to kinematic dynamic rotation MR dislocation. Surgically, ECU subluxation was observed in 13 cases, dislocation was observed in 12 cases that showed DR-MR and ECU tendon subluxation and dislocation was observed in the correct ratio, between $90 \%$ and $100 \%$ (32). Considering the contributions of the dynamic MR examination reported in the current studies, the inability of the static MR examination in our study to suggest that routine use in ECU instability will not go beyond providing differential diagnosis.

In this context, USG and Dynamic MR modalities that have been reported in the literature with different studies can be considered in the foreground in the diagnosis of ECU instability.

Dynamic MR shots are not cost effective, are not easily accessible, and have handicaps such as long appointment times for shooting. For this reason, USG seems practically more applicable.

Sole et al. reported acceptable diagnostic rates in 26 asymptomatic tennis players with dynamic and static USG evaluation (33). Lee et al. determined a standard position of ECU instability in USG assessment of the ECU tendon in 40 volunteers who were healthy and asymptomatic (flexion, supination, ulnar deviation) (23). Furthermore, Pratt et al. applied the USG technique with standard measurement and parameters to evaluate ECU subluxation in 10 asymptomatic volunteers (24). In a study of 39 symptomatic cases with chronic ulnar-sided dorsal wrist pain in 40 wrists, Sato et al. concluded that the correct diagnosis would be made by the combination of a clinical provocation test (synergy) and the USG method (19). USG examination, which is easier to reach, can be used more widely in case of clinical suspicion.

Campbell et al. propose that USG is the most suitable imaging method for determining the diagnosis and treatment plan in clinically suspected cases (27). Since the ECU tendon is very superficial and dynamically the effects of wrist movements on tendon and ulnar groove can be evaluated directly by USG, it is thought that USG is a more suitable modality. An ultrasound practitioner ex-perienced in the musculoskeletal system will also detect tendinopathy, synovial hypertrophy and inflammation.

The result of our study suggests that ultrasonography is the model that will guide diagnosistreatment and provide a correct diagnosis rate in patients suspected of ECU instability and other ECU pathologies.

Although our study is relatively strong in comparison with the literature, the number of cases evaluated makes it difficult to generalize. However, in our healthy and asymptomatic group, our observation of the presence of instability in the ECU tendon is important for asymptomatic cases. The strength of our study compared to previous retrospective publications is that the patients are examined in detail in terms of ECU tendon instability, the positivity of the provocation test is tested and then the patients are directed to MR for diagnosis. At the same time, another strength of the studies lies in the cases where MR was requested in terms of both the control group and ECU instability, and the application of a random method separately in pronation, supination and neutral positions instead of a fixed position.

The fact that MRI could not be performed in all three positions in the same cases due to difficulty in obtaining the approval of the ethics committee is the main deficiency of our study.

Our study suggests that ECU instability in MR is not a specific condition, and detection of MR in instability may not be associated with a patient's symptoms.

Although it is clinically symptomatic and the provocation test is positive, MR imaging is an unnecessary and expensive method for diagnosis in a patient with ECU instability. Dynamic USG or dynamic MR tests are more preferable in the diagnosis of ECU instability.

\section{REFERENCES}

1. Salva-Coll G, Garcia-Elias M, Leon-Lopez M, LlusaPerez M, Rodríguez-Baeza A. Role of the extensor carpi ulnaris and its sheath on dynamic carpal stability. $J$ Hand Surg Eur. 2012 ; 37 : 544-8. 
2. Taleisnik J, Gelberman RH, Miller BW, Szabo RM. The extensor retinaculum of the wrist. Hand Surg. 1984 ; 9 : 495-501.

3. Iwamoto A, Morris RP, Andersen C, Patterson RM, Viegas SF. An anatomic and biomechanic study of the wrist extensor retinaculum septa and tendon compartments. J Hand Surg. 2006 ; 31 : 896-903.

4. Montalvan B, Parier J, Brasseur J, Viet D, Drape J. Extensor carpi ulnaris injuries in tennis players : a study of 28 cases. Br J Sports Med. 2006 ; 40 : 424-9.

5. Wang C, Gill TJ, Zarins B, Herndon JH. Extensor carpi ulnaris tendon rupture in an ice hockey player: a case report. Am J Sports Med. 2003 ; 31 : 459-61.

6. Garcia-Elias M. Tendinopathies of the extensor carpi ulnaris. Handchir Mikrochir P. 2015 ; 47 : 312-5.

7. De Quervain in La Chaux-de-Fonds F. On a form of chronic tendovaginitis. Hand Surg. 2005 ; 30 : 388-91.

8. Inoue G, Tamura Y. Recurrent dislocation of the extensor carpi ulnaris tendon. Br J Sports Med. 1998 ; 32 : 172-4.

9. Hawkes R, O'Connor P, Campbell D. The prevalence, variety and impact of wrist problems in elite professional golfers on the European Tour. Br J Sports Med. 2013 ; 47 : 1075-9.

10. Eckhardt WA, Palmer AK. Recurrent dislocation of extensor carpi ulnaris tendon. Hand Surg. 1981 ; $6: 629-31$.

11. Rowland SA. Acute traumatic subluxation of the extensor carpi ulnaris tendon at the wrist. Hand Surg. 1986; 11 : 809-11.

12. Kuntz MT, Janssen SJ, Ring D. Incidental signal changes in the extensor carpi ulnaris on MRI. Hand. $2015 ; 10: 750$ 5.

13. Levy SM, Reid M, Montgomery A-M, Botterill E, Kovalchik SA, Omizzolo M, et al. Do magnetic resonance imaging abnormalities of the non-dominant wrist correlate with ulnar-sided wrist pain in elite tennis players? Skelet Radiol. 2020 ; 49 : 407-15.

14. Trickey J, Sahbudin I, Bortoluzzi A, Iagnocco A, Pineda C, Sifuentes-Cantú C, et al. THU0621 very low prevalence of ultrasound determined tendon abnormalities in healthy subjects throughout the age range : OMERACT ultrasound minimal disease study. BMJ Publishing Group Ltd ; 2019.

15. Wolfe SW, Hotchkiss RN, Pederson WC, Kozin SH. Green's Operative Hand Surgery E-Book : Expert Consult : Online and Print : Elsevier Health Sciences ; 2010.

16. Salva-Coll G, Garcia-Elias M, Leon-Lopez M, LlusaPerez M, Rodríguez-Baeza A. Effects of forearm muscles on carpal stability. J Hand Surg Eur. 2011 ; 36 : 553-9.

17. Buterbaugh GA, Brown TR, Horn PC. Ulnar-sided wrist pain in athletes. Clin Sports Med. 1998 ; 17 : 567-83.

18. Rettig AC. Athletic injuries of the wrist and hand : part II : overuse injuries of the wrist and traumatic injuries to the hand. Am J Sports Med. 2004 ; 32 : 262-73.

19. Sato J, Ishii Y, Noguchi H. Diagnostic Performance of the Extensor Carpi Ulnaris (ECU) Synergy Test to Detect
Sonographic ECU Abnormalities in Chronic Dorsal UlnarSided Wrist Pain. J Ultrasound Med. 2016 ; 35 : 7-14.

20. Iorio ML, Bayomy AF, Huang JI. Morphology of the extensor carpi ulnaris groove and tendon. Hand Surg. $2014 ; 39: 2412-6$.

21. Buck FM, Nico MA, Gheno R, Haghighi P, Trudell DJ, Resnick D. Morphology of the distal radioulnar joint : cadaveric study with MRI and MR arthrography with the forearm in neutral position, pronation, and supination. $\mathrm{Am} \mathrm{J}$ Roentgenol. 2010 ; 194 : W202-W7.

22. Petchprapa CN, Meraj S, Jain N. ECU tendon "dislocation" in asymptomatic volunteers. Skelet Radiol. $2016 ; 45: 805-12$.

23. Lee KS, Ablove RH, Singh S, De Smet AA, Haaland B, Fine JP. Ultrasound imaging of normal displacement of the Extensor Carpi Ulnaris tendon within the ulnar groove in 12 forearm-wrist positions. Am J Roentgenol. 2009 ; 1933 : 651-5.

24. Pratt R, Hoy G, Bass Franzer C. Extensor carpi ulnaris subluxation or dislocation? Ultrasound measurement of tendon excursion and normal values. Hand Surg. 2004 ; 9 : 137-43.

25. Ruland RT, Hogan CJ. The ECU synergy test : an aid to diagnose ECU tendonitis. Hand Surg. 2008 ; 33 : 1777-82.

26. Toprak U, Turkoglu S. Anthropometric and clinical analysis of the distal ulna and extensor carpi ulnaris tendon using MRI. Surg Radiol Anat. 2018 ; 40 : 989-94.

27. Campbell D, Campbell R, O'Connor P, Hawkes R. Sports-related extensor carpi ulnaris pathology : a review of functional anatomy, sports injury and management. $\mathrm{Br} J$ Sports Med. 2013 ; 47 : 1105-11.

28. Singh R, Patel A, Roulohamin N, Turner R. A classification for extensor carpi ulnaris groove morphology as an aid for ulnar sided wrist pain. J Hand Surg Asian Pac Vol. $2016 ; 21: 246-52$.

29. Jeantroux $J$, Becce $F$, Guerini $H$, Montalvan B, Le Viet D, Drapé J-L. Athletic injuries of the extensor carpi ulnaris subsheath : MRI findings and utility of gadoliniumenhanced fat-saturated T1-weighted sequences with wrist pronation and supination. Eur Radiol. 2011 ; 21 : 160-6.

30. Burgess RA, Pavlosky WF, Thompson RT. MRIidentified abnormalities and wrist range of motion in asymptomatic versus symptomatic computer users. $B M C$ Musculoskelet Disord. $2010 ; 11: 273$.

31. Boutin RD, Buonocore MH, Immerman I, Ashwell Z, Sonico GJ, Szabo RM, et al. Real-time magnetic resonance imaging (MRI) during active wrist motion initial observations. PLoS One. $2013 ; 8$.

32. Kaiser P, Kellermann F, Arora R, Henninger B, Rudisch A. Diagnosing extensor carpi ulnaris tendon dislocation with dynamic rotation MRI of the wrist. Clin Imaging. 2018 ; $51: 323-6$.

33. Sole JS, Wisniewski SJ, Newcomer KL, Maida E, Smith J. Sonographic evaluation of the extensor carpi ulnaris in asymptomatic tennis players. $P M \& R$. $2015 ; 7$ : 255-63. 